\title{
VIX and VIX Futures Pricing Algorithms: Cultivating Understanding
}

\author{
G. D’Anne Hancock \\ Finance University of Missouri-St. Louis, St. Louis, USA \\ Email: gdweise@umsl.edu
}

Received April 2, 2012; revised April 19, 2012; accepted May 3, 2012

\begin{abstract}
This article reviews the development of the S\&P 500 volatility index and uses market information to develop algorithms which aid in clarifying some of the salient points in the determination of an index value. Understanding the pertinent points provides insight into the interpretation and limitations of the usefulness of the VIX and other VIX-type contracts.
\end{abstract}

Keywords: VIX Pricing; VIX Futures; VIX Options; Volatility Index

\section{Introduction}

This article reviews the development of the S\&P 500 volatility index and the VIX futures contracts using market information to develop algorithms that aid in clarifying some of the central points in the determination of a value. Understanding the salient points provides insight into the interpretation and limitations of the usefulness of the VIX and VIX-type contracts. Instructing students in the specifics of the relatively new volatility indices such as the VIX poses several difficulties due to the intricate calculations required to obtain a value. The purpose of this paper is to present algorithms for pricing the VIX and VIX futures in order to improve understanding of the components necessary to obtain the end result. This lays the groundwork for understanding and interpreting the limitations of the index. The confines of a VIX option algorithm are also addressed as an ancillary topic.

There has been much written in the literature on the need to bridge the gap between education and the professional field [1-3]. Charles and Joseph (2009) express this as an increasing need for business programs to provide their graduates with relevant competences and skills necessary to succeed in an extremely competitive business environment [3]. In the technical field of finance increased awareness often involves moving beyond definitions and abstractions to concrete hands-on practice. As such, the algorithms presented in this paper are applied to market data to demonstrate the practical application.

To date the vast majority of the literature on the VIX and VIX-type instruments has been published by the Chicago Board Options Exchange (CBOE) and other exchanges offering the contracts for trade. There has been virtually no independent investigation related to the feasibility of instructing on VIX-type concepts. This article fills the gap between the theoretical and the practical with classroom tested algorithms.

The establishment and development of the VIX is first discussed, followed by the development of two separate pricing algorithms, one each for the: VIX and VIX futures contracts. Finally, VIX options are discussed in conjunction with the limitations of a useful algorithm.

\section{Establishment of VIX}

In 1993, the Chicago Board Options Exchange introduced the CBOE Volatility Index (VIX), which was originally designed to measure the market's expectation of 30-day volatility implied by at-the-money S\&P 100 Index (OEX) option prices. Unlike VIX options and futures, the VIX is not a tradable financial security; instead, it is used as a benchmark for U.S. stock market volatility and is frequently referred to as the fear index in the popular press. The idea behind the VIX was introduced in 1993 by Professor Robert Whaley of Duke University. Professor Whaley's (1993) calculations are slightly different than those currently employed but the substance remains the same [4]. In 2003, Sandy Rattray and Devesh Shah (Goldman Sachs) along with the CBOE updated the VIX using the S\&P 500 (SPX) option index. The new procedure requires averaging the weighted prices of the SPX puts and calls over a wide range of out-of-themoney strike prices. This methodology made it possible to transform the VIX from an abstract concept into a realist standard for trading and hedging volatility.

Less than a year after the calculations were revised, tradable futures contracts on the volatility of the S\&P 500 index were created by the CBOE (2004) and are traded 
on the CBOE Chicago Futures Exchange (CBOE-CFE). This distinctive contract was the first to offer investors the ability trade on the risk of the market as a whole and won an award for innovation [5]. Two years after the introduction of VIX futures, in February 2006, the CBOE introduced options on the S\&P 500 VIX and, to date, they are the most successful new product in CBOE history. By 2008, the combined trading activity in VIX options and futures had grown to more than 100,000 contracts per day.

One of the main, documented benefits of trading VIXtype contracts is its negative correlation with movements in the market. The inverse relationship between market volatility and stock market returns is well documented and suggests a diversification benefit which implies that including volatility as a diversification asset can significantly reduce portfolio risk [6,7]. VIX futures and options are designed to deliver pure volatility exposure in a single, efficient package. The volatility of the VIX is about four times as great as the underlying cash index and is referred to as the volatility of volatility. The average value of the VIX in 2010 was 21.6070 and is 24.66, to date, in 2011 on all available S\&P 500 option contracts. Higher VIX levels indicate that the market's anticipation of 30-day forward volatility is increased. Some argue that this also indicates greater fear in the market. However, there is no research showing a direct relationship between increased standard deviation of stock returns and market fear. The fear index is generally believed to conform to the following interpretations:

\section{FEAR INDEX:}

5-10 = extreme complacency

$10-15=$ very low anxiety $=$ high complacency

$15-20=$ low anxiety $=$ moderate complacency

20-25 = moderate anxiety = low complacency

25-30 = moderately high anxiety

30-35 = high anxiety

$35-40=$ very high anxiety

40-45 = extremely high anxiety

$45-50=$ near panic

50-55 = moderate panic

$55-60=$ panic

60-65 = intense panic

$65+=$ extreme panic

The implied volatility of the market can be calculated iteratively using the Newton-Raphson technique based on the Black-Scholes model but no general model or approach is theoretically accepted [8]. Even so, the CBOE approach to the VIX calculation is accepted by the market as a practical norm. It is noteworthy that options with different strike prices, but identical expiration dates, trade at different implied volatilities - this phenomenon is known as the implied volatility smile and is characterized by a return distribution with fat tails [9]. The volatility skew is indicative of the return distribution asymmetry. The name smile applies because the graph of implied volatilities relative to the expiration date, or the volatility term structure, tends to have the shape of a grin. The volatility term structure identifies the relationship between implied volatilities and time to expiration which provides another tool for traders to gauge cheap or expensive options. Much has been written on a wide variety of issues surrounding the volatility smile and skewness suggesting that as volatility in the overall market or in a particular stock increases, the probability of extreme price movements strengthens as well [10-12]. The VIX calculation incorporates the volatility smile, the volatility skew and, to a lesser degree, the volatility term structure.

In addition to the VIX, the CBOE offers several other volatility indexes including the CBOE Nasdaq-100 Volatility Index (VXNSM), CBOE DJIA Volatility Index (VXDSM), CBOE Russell 2000 Volatility Index (RVXSM) and CBOE S\&P 500 ${ }^{\circledR}$ 3-Month Volatility Index (VXVSM).

\section{Pricing the VIX}

The CBOE utilizes a wide variety of strike prices for SPX puts and calls to calculate the 30-day implied volatility value for VIX as well as the other VIX-type contracts. The calculation blends options expiring in two consecutive months, the near-term and the next-term, with out-of-the-money options to obtain a final market volatility level. The relevant measure of risk for pricing options in the traditional Black and Scholes (1973) framework is the volatility of the underlying stock while the option is alive [12]. As such, embedded in the option premium is a measure of the stock's future volatility during the holding period. Therefore, the premise of the VIX, given a set of option premiums, strikes and expiration dates, the underlying volatility of the stock can be ascertained.

When options are written on market indices, the premiums reflect the expected volatility of the underlying market, as defined by the index. VIX measures the anticipated market volatility in either direction; downside as well as upside. In practical terms, when investors anticipate large upside volatility, they are unwilling to sell upside call options unless they receive a large premium. Option buyers will be willing to pay the higher premiums only if similarly anticipating a large upside move. The resulting increase in upside call prices elevates the VIX and the increase in downside put premiums reduces the VIX. When the market is believed as likely to increase as to decrease, writing any option that will cost the writer in the event of a sudden large move in either direction will look equally risky.

High VIX readings mean investors see significant risk that the market will move sharply, but does not signal the 
direction of movement. Only when investors perceive neither significant downside risk nor significant upside potential will the VIX have a low value. The generalized algorithm used in the VIX calculation is shown in Figure 1. where:

$\mathrm{N}_{\mathrm{T} 1}=$ number of minutes to settlement of the nearterm options;

$\mathrm{N}_{\mathrm{T} 2}=$ number of minutes to settlement of the next -term options;

$\mathrm{N}_{30}=$ number of minutes in 30 days $(43,200)$;

$\mathrm{N}_{365}=$ number of minutes in 365 days $(525,600)$;

$\mathrm{T}_{1}=$ number of minutes until expiration of the nearterm contract as a proportion of the number of minutes in a year;

$\mathrm{T}_{2}=$ number of minutes until expiration of the nextterm contract as a proportion of the number of minutes in a year;

$\sigma_{1}^{2}=$ variance of out-of-money options expiring at time $\mathrm{T}_{1}$;

$\sigma_{2}^{2}=$ variance of out-of-money options expiring at time $T_{2}$, where the variances are obtained as specified by Equation (1.a).

$\mathrm{n}=$ the number of out-of-the-money options with nonzero bid prices;

$r_{t}=$ the coupon-equivalent yield on the T-bill maturing closest to the $t^{\text {th }}$ option's expiration;

$F_{t}=$ forward index level derived from the index option prices at-the-money for the $t^{\text {th }}$ expiration shown in Equation (1.a.i).

$\mathrm{X}_{\mathrm{t}, \mathrm{o}}=$ first strike below the forward index level;

$\mathrm{X}_{\mathrm{t}, \mathrm{i}}=$ strike price of $\mathrm{i}^{\text {th }}$ out-of-the-money option with expiration $\mathrm{t}$ : a call if $\mathrm{X}_{\mathrm{i}, \mathrm{t}}>\mathrm{X}_{\mathrm{ott}}$ and a put if $\mathrm{X}_{\mathrm{i}, \mathrm{t}}<\mathrm{X}_{\mathrm{o}, \mathrm{t}}$. Both put and call if $\mathrm{X}_{\mathrm{i}, \mathrm{t}}=\mathrm{X}_{\mathrm{o}, \mathrm{t}}$. The number of "i" options depends on the number of out-of-the-money options that trade with non-zero bid prices with expiration $\mathrm{t}$;

$\Delta \mathrm{X}_{\mathrm{t}, \mathrm{I}}=$ the interval between strike prices on either side of $\mathrm{X}_{\mathrm{o}, \mathrm{t}}$ shown in Equation (1.a.ii);

$\mathrm{Q}\left(\mathrm{X}_{\mathrm{t}, \mathrm{i}}\right)=$ the midpoint of the bid-ask spread for each out-of-money option with strike $\mathrm{X}_{\mathrm{i}}$, where the call midpoint is: $\mathrm{C}_{\mathrm{m}}=\left(\mathrm{C}_{\mathrm{b}}+\mathrm{C}_{\mathrm{a}}\right) / 2$; and the put midpoint is: $\mathrm{P}_{\mathrm{m}}=$ $\left(\mathrm{P}_{\mathrm{a}}+\mathrm{P}_{\mathrm{b}}\right) / 2$.

To begin the VIX calculation, the inputs for Equation (1.a.) are first identified in order to calculate the variance of the out-of-money options for the near-term and next-term contract months. The near contract is the contract which will expire soonest. The current month can be eliminated as the near contract when the expiration is one week or less from "now". Assume the current date is May $18^{\text {th }}, 2011$ and expiration for the current month is only three days away on May $21^{\text {st }}$ (see Appendix A). The expiration date is less than one week away so May is eliminated from the observation set in this example. The near-term contract month is Jun $11(\mathrm{t}=1)$ and the next-term contract month is Jul $11(\mathrm{t}=2)$. Throughout, note that the VIX calculation utilizes the mid-point of the bid-asked premiums as pricing inputs.

Using the SPX option quotations in Table 1, the strike price with the smallest difference between the call and put mid-points for both months (Jun and Jul) must be identified in order to solve for $F_{t}$, Equation 1.a.i. Usually this will be the closest to at-the-money option. The SPX cash index level is 1334.97 and the strike associated with the smallest difference between the call mid-points, $\mathrm{C}_{\mathrm{t}, \mathrm{o}}$, and put mid-points, $\mathrm{P}_{\mathrm{t} . \mathrm{o}}$, for the near contract is the 1330 :

$\mathrm{X}=1300 \mathrm{C}_{\mathrm{t}, \mathrm{o}}=(20.70+24.20) / 2=23.45$

$\mathrm{X}=1300 \mathrm{P}_{\mathrm{t}, \mathrm{o}}=(20+22) / 2=21$

Difference $\$ 2.45$

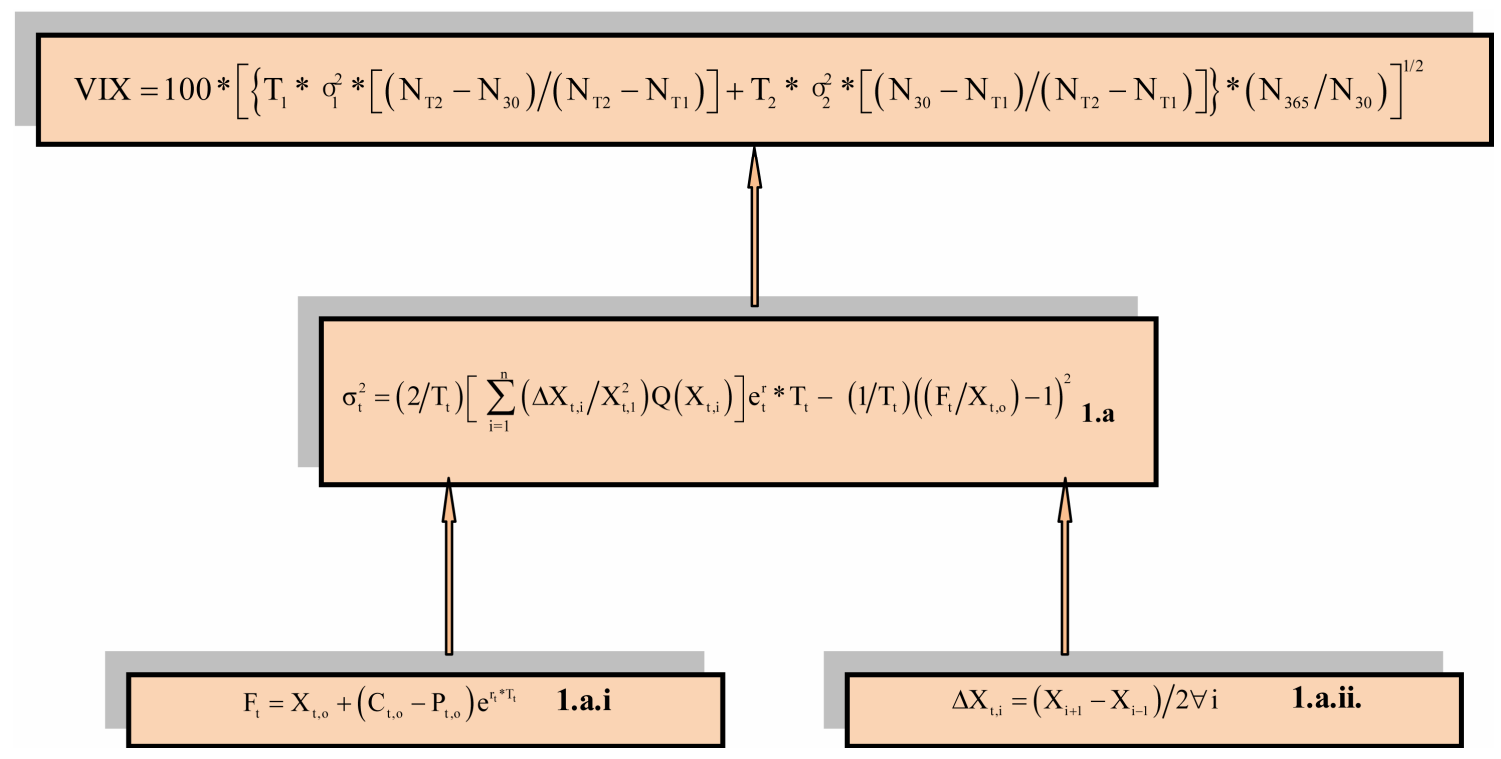

Figure 1. The VIX pricing algorithm. 
Table 1. VIX data inputs.

May 18, $2011 @ 12: 21$ ET

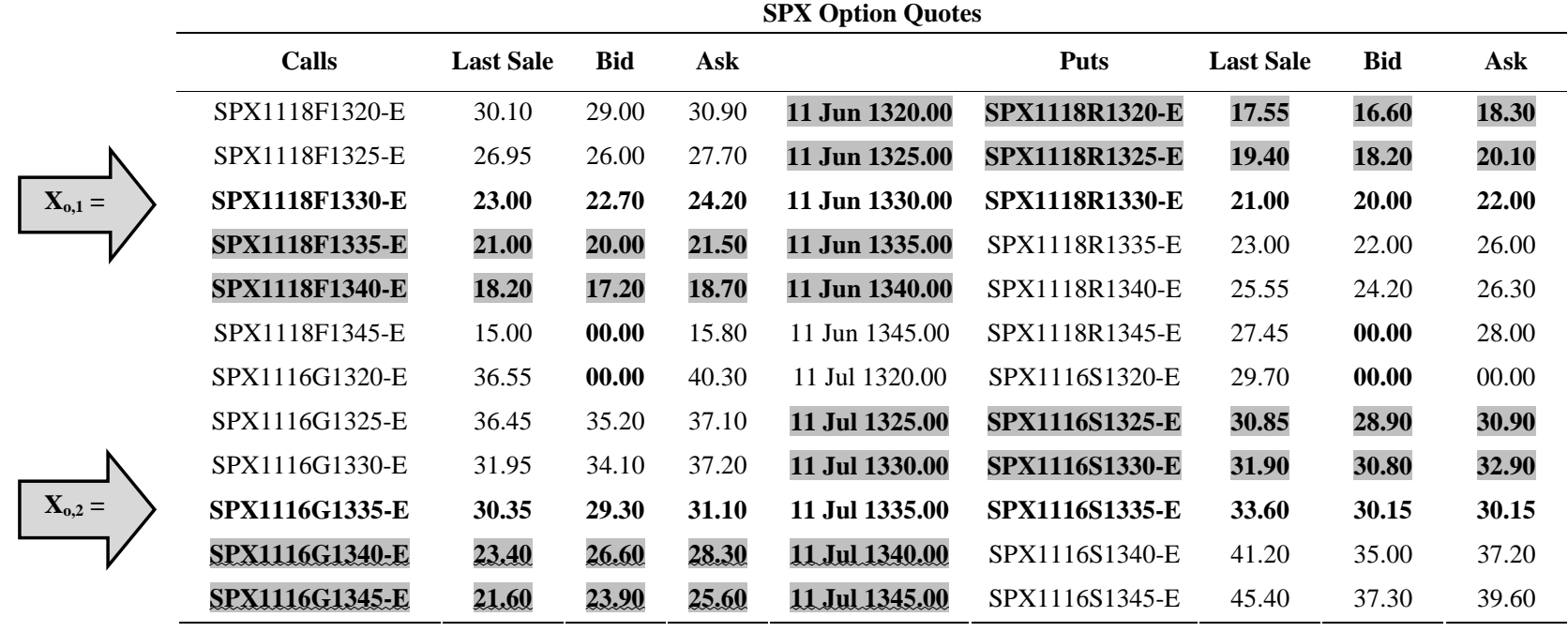

Other mid-point differences are larger than $\$ 2.45$ so those strike prices are not used as inputs into Equation (1.a.i) This same process is repeated for the next-term, July. The smallest difference in July premiums is associated with the 1335 strike. Notice that two different risk-free rates, shown in Table 1, are needed: one fornear-term and another for the next-term options.

The last input to consider for Equation (1.a.i) is the determination of $T_{t}$ for each month. VIX measures time in terms of minutes rather than the more traditional use of days. There are four components that go into the estimate of $T_{t}$ : the number of minutes remaining in the current day (see time, 12:21 ET, in Table 1), $\mathrm{M}_{\mathrm{CD}}$, the number of minutes in the settlement day until 8:30 a.m., $\mathrm{M}_{\mathrm{SD}}$, the number of minutes in the other days between $\mathrm{CD}$ and $\mathrm{SD}, \mathrm{M}_{\mathrm{OD}}$, and the number of minutes in the year, $\mathrm{M}_{\mathrm{Y}}$.

The forward index level can now be determined for each month using Equation (1.a.i) as follows:

\section{JUNE $\left(T_{1}\right)$}

$\mathrm{M}_{\mathrm{CD}}=39$ minutes $+(11$ hours $) * 60$ minutes $=699$

$\mathrm{M}_{\mathrm{SD}}=(8$ hours $) * 60+30$ minutes $=510$

$\mathrm{M}_{\mathrm{OD}}=29$ days $* 24$ hours $* 60$ minutes $=\underline{41,760}$

Total Minutes $\underline{\underline{42,969}}$

$\mathrm{M}_{\mathrm{Y}}=365 * 24 * 60=525,600$

$$
\mathrm{T}_{1}=2969 / 525,600=\underline{0.081752283}
$$

\section{$1335 \operatorname{JULY}\left(\mathrm{T}_{2}\right)$}

$\mathrm{M}_{\mathrm{CD}}=39$ minutes $+(11$ hours $) * 60$ minutes $=699$

$\mathrm{M}_{\mathrm{SD}}=(8$ hours $) * 60+30$ minutes $=510$

$\mathrm{M}_{\mathrm{OD}}=57$ days $* 24$ hours $* 60$ minutes $=\underline{82,080}$

Total Minutes $\underline{\underline{83,289}}$

$\mathrm{M}_{\mathrm{Y}}=365 * 24 * 60=525,600$

$T_{2}=83,289 / 525,600=\underline{0.158464612}$
1330 Jun:

$$
F_{1}=1330+(23.45-21)^{*} \mathrm{e}^{0.00015^{*(42,969 / 525,600)}}=1332.45
$$

1335 Jul:

$F_{2}=1335+(30.20-30.15) * e^{0.00055 *(83,289 / 525,600)}=1335.05$

In order to keep the example manageable, only two out-of-the-money options are included in the analysis. This is contrived to be artificially low; there were, in fact, 37 different strikes with non-zero bids and on this trading day with strikes ranging from 1195-1380. The bold, shaded areas in Table $\mathbf{1}$ show the non-zero bid options relating to $\mathrm{X}_{\mathrm{t}, 0}$ for the near-term (June) and the next-term (July). Notice that $X_{t, 0}$ is the only strike at which both the put and the call mid-points are included in the analysis. For the other strike prices, when the calls are out-of-themoney the puts are in-the-money and vice versa so the analysis centers on either calls or puts but not both. The strikes $\mathrm{X}_{\mathrm{t}, \mathrm{i}}$ are:

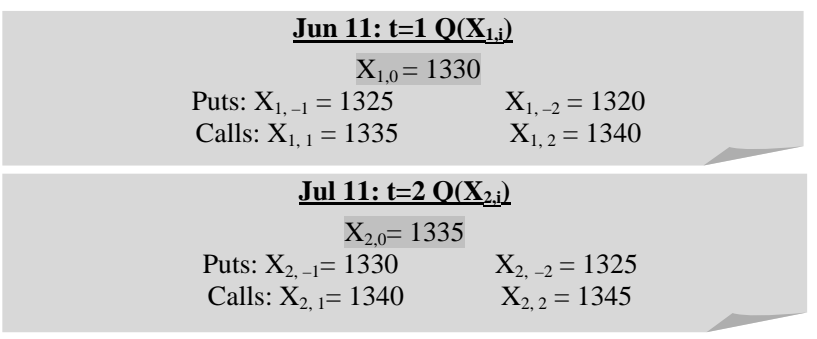

When two consecutive non-zero bids occur, no additional out-of-money options are included in the calculations. It follows that the number of options included in the VIX calculation will differ from day to day. The only variable remaining to identify as an input to Equation (1) is $\Delta \mathrm{X}_{\mathrm{t}, \mathrm{I}}$ Equation (1.a.ii). For the June contract, the interval between strike prices surrounding 1330 is: (1325 1335)/2 = 5. Likewise for the July contract, the interval 
surrounding the 1335 strike is: $(1340-1330) / 2=5$. Although the change in $X_{i}$ is the same for the Jun and Jul contracts in this example, such is not always the case. When the identified variables, $\Delta X_{t, i}, X_{t, i}, X_{t, o}, T_{1}, T_{2}$ and $F_{t}$ are input into Equation (1.a.) the solution is as shown in Figure 2 for the variance of out-of-money options for options expiring at $\mathrm{T}_{1}$ and $\mathrm{T}_{2}$.

Inserting the correct variables into Equation (1), the VIX can now be determined as follows:

An annualized VIX measure of 8.1756 means the market is anticipating an $8.1756 \%$ change in market prices over the year, either up or down. Since the VIX has a strong negative correlation to the SPX and is generally about four times more volatile than the SPX, it is a highly effective hedging instrument when properly applied. Furthermore, speculators can only establish a position on market volatility through the use of options and futures on the VIX since a direct position is not currently possible.

\section{Pricing VIX Futures}

The VIX futures contract is designed to reflect investors' consensus view of futures (30-day) expected stock market volatility. As such, a long position in a VIX futures contract simultaneously represents a bet that the volatility of the market will increase and the value of the market will decline. Like other index derivatives, the VIX futures is a cash-only settle contract. The cash settlement amount is determined on the Wednesday that is thirty days prior to the third Friday of the calendar month immediately following the month in which the contract expires (see Appendix B). The amount due is the final mark-to-market amount against the final settlement value of the VIX futures multiplied by $\$ 1000.00$.

When pricing VIX futures, the relationship is not as straightforward as for other futures contracts because there is no simple cost-of-carry, arbitrage-free relationship between the futures price, $F_{t}$, and the underlying asset, VIX $_{t}$. There is no cost-of-carry because there is no tradable asset underlying the VIX futures since the cash VIX index cannot be bought or sold. The VIX index and VIX futures are connected by a statistical relationship that depends on the speed with which the VIX moves toward its average level, the volatility of the index and the time remaining until expiration.

The relevant parameters are estimated here using the approach introduced by the CBOE-CFE. The futures value is derived by pricing the forward 30-day variance which underlies the settlement price of surrounding VIX futures. The fair value of a VIX futures contract is the square root of the implied variance minus an adjustment factor which reflects the concavity, $\mathrm{C}_{\mathrm{t}, \mathrm{f}}$ of the forward position. Figure 3 shows the VIX futures pricing algorithm symbolically:

The variable $\sigma_{\mathrm{f}}^{2}$, Equation (2.a.), is the forward variance implied by existing variances surrounding the relevant time period and $\sigma_{\mathrm{t}, \mathrm{f}}^{2}$, Equation (2.b.), is the concavity adjustment squared. Using methods similar to those on

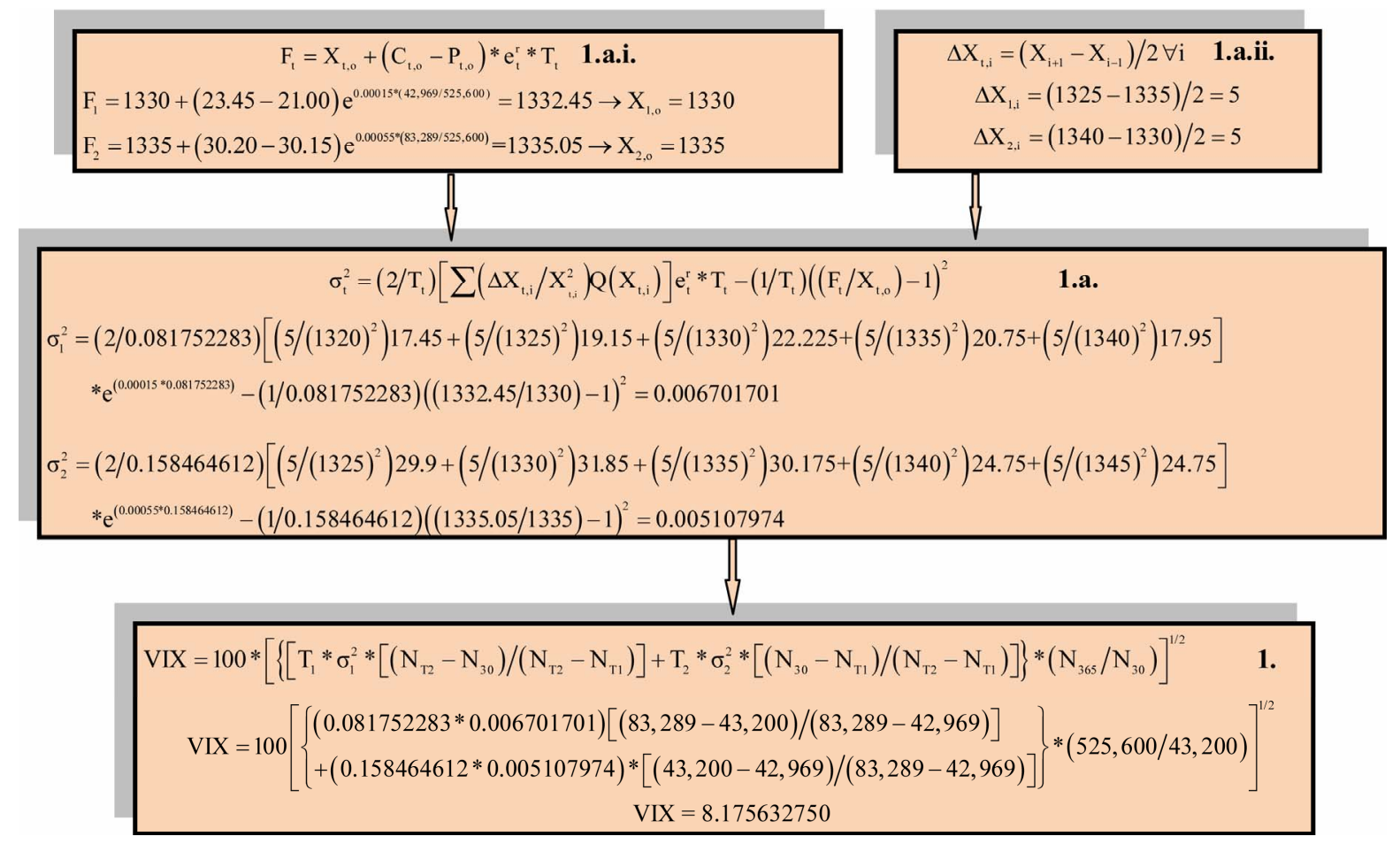

Figure 2. The VIX pricing solution. 


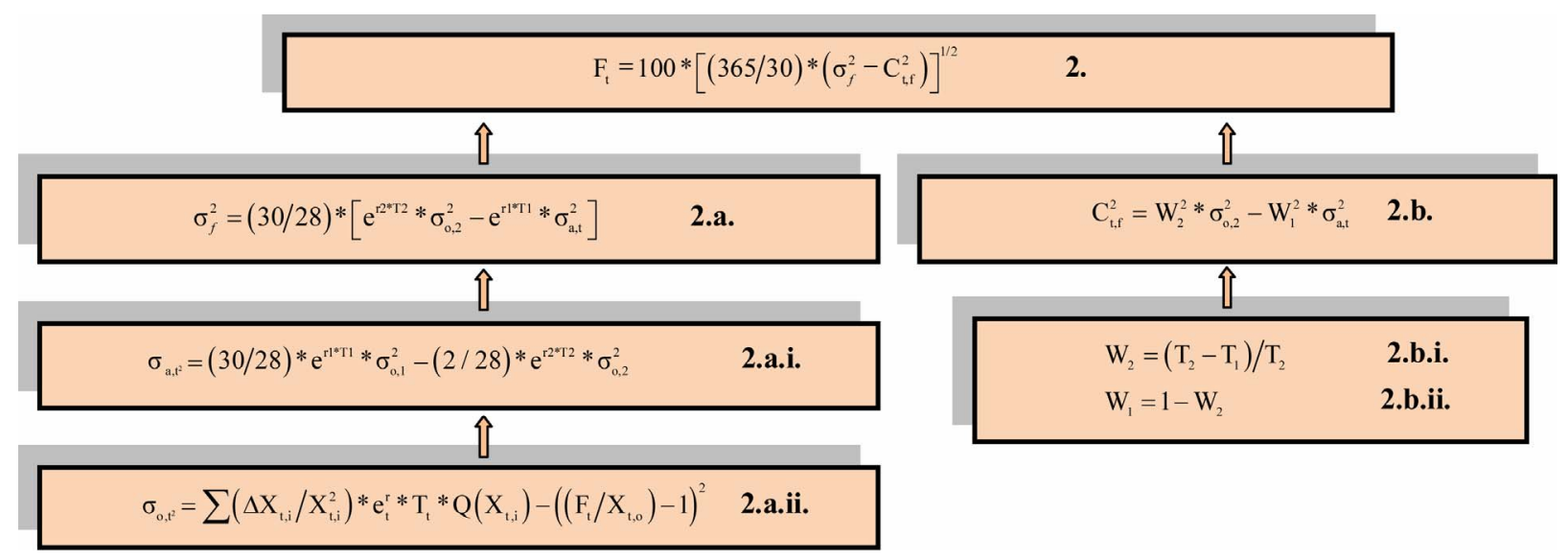

Figure 3. The VIX futures pricing algorithm.

which the calculation of VIX is based, the forward value of the 30-day variance is determined from a calendar spread of S\&P 500 options bracketing the 30 days after the futures expiration.

The variance inputs are determined using Equations (2.a.i) and (2.a.ii). The variable $\sigma_{a, t}^{2}$, Equation (2.a.i), is an adjusted variance that subtracts a 2-day overlap with the second time period. Notice that $\sigma_{\mathrm{o}, \mathrm{t}}^{2}$, Equation (2.a.ii), is equal to Equation (1.a.) except the two terms, $\left(2 / \mathrm{T}_{\mathrm{t}}\right)$ and $\left(1 / T_{t}\right)$, used to annualize the results have been omitted.

The convexity input is obtained as the weighted difference between the next-term contract variance and the near-term contract variance, weighted by time, Equations (2.b.i) and (2.b.ii) An example will help highlight the factors to be considered when determining the fair futures value by solving Equations (2-2.b.ii) The solution is shown in Figure 4. Assume an analyst wishes to determine the fair value of the Jun 11 VIX futures. When the Jun 11 contract expires on Jun $15^{\text {th }}$, 2011, its final settlement price reflects implied volatility for the 30-day period from today, May $18^{\text {th }}$, until expiration, June $15^{\text {th }}$, $2011^{1}$. The fair value of the futures is the square root of the forward volatility (variance), Equation (2.a.), over this period adjusted downward by concavity.

The forward futures variance, $\sigma_{\mathrm{f}}^{2}$, is determined as the difference between the variance of the near-term contract, June, and the variance of the next-term contract, July. These two contracts comprise the calendar spread and are used to determine the implied forward variance. The time line below highlights the important dates in solving for the fair futures price and provides a visual for the spread.

The shaded grey bars on the time line represent the actual volatilities of the Jun 11 and Jul 11 contracts. The darkly shaded bar represents the forward variance implied by the existing surrounding variances. As such, solving for the forward variance is much the same as solving for

\footnotetext{
${ }^{1}$ The third Friday of the month following the delivery month is July $15^{\text {th }}$ Thirty days prior to July $15^{\text {th }}$ is June $15^{\text {th }}$.
}

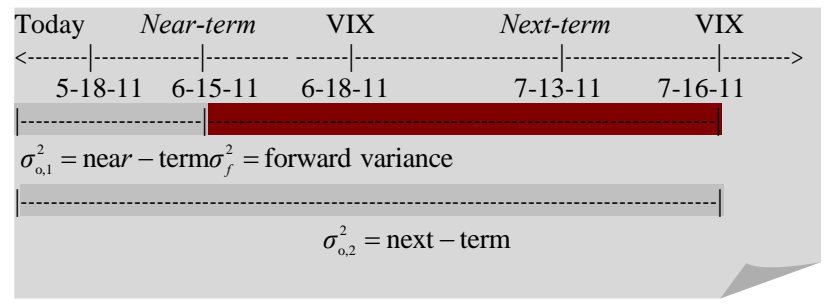

the more familiar forward rates. The calculations presented in Figure 4 demonstrate how the solution to each component feed-in to the next step. On the other side of the algorithm, labeled 2.b.-2.b.ii, the convexity inputs are considered. Finally, the solutions for the variance input and the convexity input are inserted into Equation (2) in order to obtain the fair value of the June futures or3.5898. For a near-term expiration, the futures will be close to the VIX index level and move in tandem with it, while next-term futures will reflect the long-term expectation of VIX plus a risk premium.

VIX futures track implied volatilities for successive 30-day periods, e.g. a May 2011 futures tracks the implied volatility from May 18 to June 17; a June 2011 futures tracks the implied volatility from June 15 to July 15, and so on. Contracts can be stacked to cover implied volatilities for longer periods of time. For example, a stack of May and June VIX futures tracks an approximate 60-day implied volatility (with a two-day overlap).

The term structure of implied volatility is the curve of implied volatilities for periods extending from the current date to different future dates, e.g. May 18 to Jun 15, or Jun 15 to Jul 15, and so on. Points on the curve can be estimated from option prices with matching expirations. One method is to find the Black-Scholes implied volatilities of at-the-money options. Alternatively, the implied volatilities can be calculated from the prices of strips of out-of-the-money options which replicate the variances. Similar to the term structure of interest rates, the term structure of implied volatility is generated by spot and forward volatilities, more precisely by spot and forward 


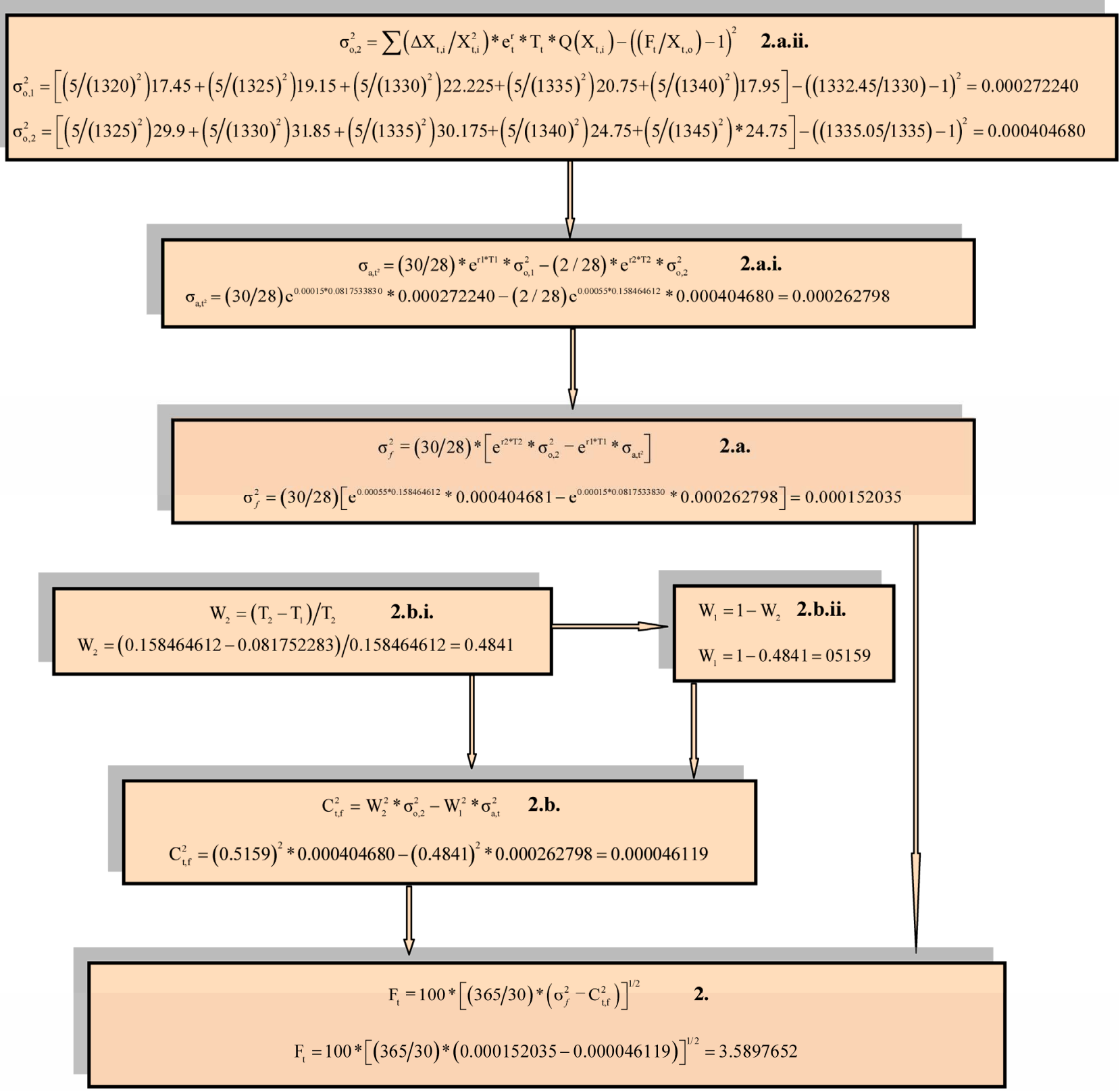

Figure 4. The VIX futures pricing solution.

variances since it is the variances which can be added, not their square roots. In light of this, VIX and VIX futures prices can be squared and pieced together to yield alternative estimates of various points of the term structure of implied volatility. Some inter- or extrapolation is required because VIX and VIX futures usually do not cover contiguous periods.

The spot-forward relationship between VIX and VIX futures has two noteworthy consequences:

1) The price of a VIX futures contract can be lower, equal to or higher than VIX, depending on whether the market expects volatility to be lower, equal to or higher in the 30-day forward period covered by the VIX futures contract than in the 30-day spot period.

2) There is no cost-of-carry relationship between the price of VIX futures and VIX. This is simply because there is no "carry" arbitrage between VIX futures and VIX as there is between a stock index futures and the underlying index. VIX is a volatility forecast, not an asset. Hence the investor cannot create a position equivalent to one in VIX futures by buying VIX and holding the position to the futures expiration date while financing the transaction.

\section{Pricing VIX Options}

Similar to a long futures position, a position in a VIX call 
option is a simultaneous bet that market volatility will increase and market value will decrease. Conversely, a position in a like put is just the reverse; a bet that market volatility will decrease and market value will increase. The settlement value for VIX options is based on a special opening quotation calculated from a sequence of opening prices of the options used to calculate the index. Exercising the option results in the exchange of cash on the day after the expiration date, with the settlement amount equal to the difference between the settlement value of VIX and the strike multiplied by $\$ 100$.

There are several important factors to consider which affect VIX option pricing which differ from other option pricing: 1) mean reversion of volatility; 2) jumps in the S\&P 500 index; 3) volatility of the S\&P 500; 4) stochastic VIX volatility; 5) cost-of-carry and the 6) settlement procedure. None of the current VIX option pricing models incorporate all six variables. A brief description of each variable follows and then one of several models is presented in an effort to highlight some of the complexities.

Pricing VIX options is complex way beyond that of stock options. When valuing VIX options, adjustments must be made to existing option pricing models because of the characteristics mentioned above. There is no model that incorporates all of the VIX features into a pricing function; the best model remains an empirical question. However, Wang and Daigler (2011) argue that Whaley's (1993) approach prices both in-the-money and at-the-money options accurately in terms of both low percentage error and dollar error [13]. However, out-ofthe-money contracts show large errors.

Whaley's simplified option pricing model is applied in this section in order to ascertain the relevant factors, and their weaknesses due to measurement error, to be considered. Whaley assumes that the underlying cash VIX follows a Geometric Brownian Motion and utilizes the theoretic development of Black (1976) for options on futures [14]. Given the underlying VIX futures the premium of a VIX call option can be expressed as follows:

Where all variables are as previously defined and two variables need more explanation:

\section{1) $\mathbf{F}_{\mathbf{o}}$}

Wang and Daigler (2011) argue that Whaley's model can be appropriately applied using either the cash VIX value or the futures value [15]. VIX option contracts are

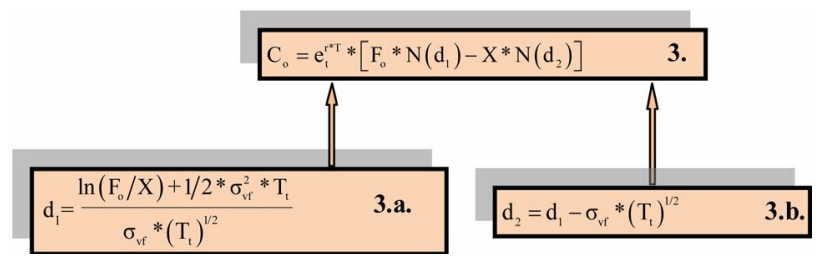

Figure 5. The VIX option pricing algorithm. unique in that there is no underlying asset. The lack of an underlying asset implies that there is no cost-of-carry so the futures price is equal to the cash price. VIX option prices should reflect the forward value of volatility. If the spot VIX experiences a big up move, call option prices will not increase as much as one would expect. Depending on the value of forward VIX, call prices might not rise at all, or could even fall. As time passes, the options used to calculate spot VIX gradually converge with the options used to estimate forward VIX. Finally, at VIX option expirations, the SPX options used to calculate VIX are the same as the SPX options used to calculate the exercise settlement value for VIX options. Hence, in this example and consistent with the CBOE practices, futures are selected rather than the cash VIX because they more accurately measure the anticipated level of the VIX at expiration.

\section{2) $\sigma_{\mathrm{vf}}$}

There are a plethora of problems associated with the appropriate measure of the future volatility, $\sigma_{\mathrm{vf}}$, of VIX. The behavior of the volatility of the underlying VIX exhibits mean-reversion tendencies after a jump-diffusion process. This means that the volatility of VIX tends to revert back to an average or mean value after a market shock has occurred. To date, option pricing models have not successfully incorporated this feature. In addition, the effect of an echo-volatility has been observed in the VIX which also has not been successfully modeled. Meanreversion drifts are more pronounced the longer the time to option expiration. Spikes in the VIX do not normally last for long before returning to within the range of normal. Unless the expiration date is very near, the market will take into account the mean-reverting nature of the VIX when estimating the forward VIX. This means that VIX call options appear heavily discounted whenever the VIX spikes. An accurate option pricing model would need to incorporate this behavior into the function. Finally, the VIX exhibits stochastic variance which, by definition is difficult to model and violates a basic BSOP assumption. For all these reasons, as well as others, the appropriate measure of volatility is a hurdle not yet overcome. For purposes of this example, the relevant measure of volatility is proxied using daily returns on the VIX and is equal to $6.3922 \%$. Interestingly, this is more than six times higher than the S\&P 500 over the same time pe- riod.

Using the information in Table 1, the relevant inputs for valuing the 2011 Jun 19 VIX call option are as follows:

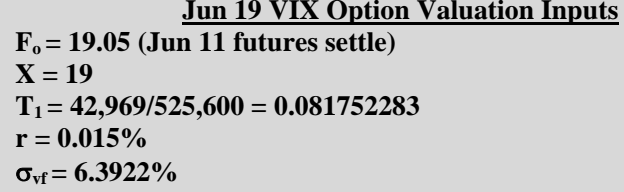




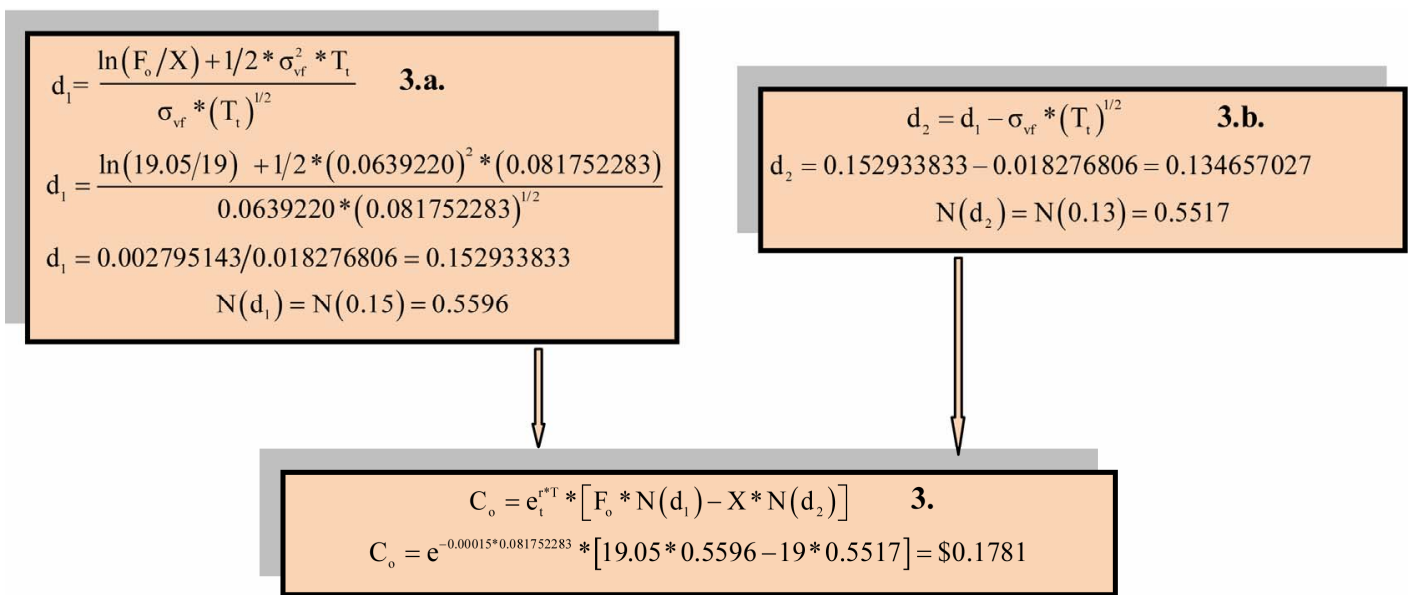

Figure 6. The VIX option pricing solution.

Note that the minutes until option expiration is identical the minutes until the VIX futures delivery (see Appendix C). Figure 6 shows the solution for the call premium when the above variables are inserted into Equations (3-3.b.) Investors cannot use the \$0.1781 solution for trading purposes due to the problems associated with the estimated variance, $\sigma_{\mathrm{vf}}$. Instead, the usefulness of this exercise lies in understanding how various inputs influence VIX option premiums.

Beyond the problems already mentioned, practical applicability of the Whaley model is limited because VIX options represent a second derivative, therefore, standard pricing models based on the original Black-Sholes (1973) formula cannot be directly applied. This characteristic implies that the upper and lower tails of VIX options are much fatter than individual equity options. In addition, since volatility is mean reverting, even when it does spike sharply, it is not likely to remain there for very long but will bias a traditional measure of variance. To date, no theoretic model has been successfully designed to capture all the features of VIX option pricing [15].

\section{Summary}

This paper presents two algorithms for pricing the VIX and VIX futures. Given the complexity of the VIX calculations, classroom presentation of the material can lead to confusion without a context for understanding the direction of the work. The algorithms presented offer professors a framework for cultivating understanding of the VIX and VIX futures. For students, this exercise goes beyond classroom theory by introducing algorithms which can be applied to any financial security on which options trade. This opens the door to the development of volatileity models on instruments of particular interest to a given business.

A major benefit to investors is the ability to add an asset which is negatively correlated with movements in the market thereby providing the means to significantly reducing overall portfolio risk. Early approaches to determining implied volatility were based on an iterative solution to the BSOP model while the VIX approach uses a wide range of out-of-the-money options in a close-form model. The closed-form makes it possible to transform the VIX from an abstract concept into a realist standard for trading and hedging volatility.

To date the vast majority of the literature on the VIX and VIX-type instruments has been published by the exchanges offering the contracts for trade. There has been virtually no independent investigation related to the feasibility of classroom instruction of VIX-type concepts.

\section{REFERENCES}

[1] F. A. J. Korthagen and J. P. Kessels, "Linking Theory and Practice: Changing the Pedagogy of Teacher Education,” Educational Researcher, Vol. 28, No. 4, 1999, pp. 4-17.

[2] S. Eric, "The Gap between Theory and Practice," MIT Sloan, Cambridge, 2008.

[3] W. Charles and M. Joseph, "Innovative Instructional Methods for Technical Subject Matter with Non-Technical Pedagogy: A Statistical Analysis,” Advances in Management, Vol. 2, No. 4, 2009, pp. 57-65.

[4] R. E. Whaley, "Derivatives on Market Volatility: Hedging Tools Long Overdue,” Journal of Derivatives, Vol. 1, No. 1, 1993, pp. 71-84. doi:10.3905/jod.1993.407868

[5] "Educational Innovation in Economics and Business," 17th EDiNEB Conference, 9-11 June 2010.

[6] P. Dennis, M. Stewart and C. Stivers, "Stock Reports, Implied Volatility Invvovations and the Asymmetric Volatility Phenomenon," Journal of Finance and Quantitative Analysis, Vol. 41, No. 2, 2006, pp. 381-407. doi:10.1017/S0022109000002118

[7] M. W. Brandt and Q. Kang, "On the Relationship between the Conditional Mean and Volatility of Stock Returns: A Latent VAR Approach,” Journal of Financial Economics, 
Vol. 72, No. 2, 2004, pp. 217-257. doi:10.1016/j.jfineco.2002.06.001

[8] T. J. Ypma, "Historical Development of the Newton-Raphson Method,” SIAM Review, Vol. 37, No. 4, 1995, pp. 531551. doi:10.1137/1037125

[9] E. Derman and K. Iraj, "Riding the Smile," Journal of Risk, Vol. 7, No. 2, 1994, pp. 32-39.

[10] C. Corrado and S. Tie, "Skewness and Kurtosis in S\&P 500 Index Returns Implied by Option Prices,” Journal of Financial Research, Vol. 19, No. 2, 1996, pp. 175-192.

[11] I. Peña, G. Rubio and G. Serna, "Why do We Smile? On the Determinants of the Implied Volatility Function," Journal of Banking and Finance, Vol. 23, No. 8, 1999, pp. 1151-1179. doi:10.1016/S0378-4266(98)00134-4
[12] F. Black and S. Myron, "The Pricing of Options and Corporate Liabilities,” Journal of Political Economy, Vol. 81, No. 3, 1973, pp. 637-654. doi:10.1086/260062

[13] Z. G. Wang and D. Robert, “The Performance of VIX Option Pricing Models: Empirical Evidence beyond Simulation,” Journal of Futures Markets, Vol. 31, No. 3, 2011, pp. 251-281.

[14] F. Black, “The Pricing of Commodity Contracts,” Journal of Financial Economics, Vol. 3, No. 1-2, 1976, pp. 167-179. doi:10.1016/0304-405X(76)90024-6

[15] Y. Lin and C. Chang, "VIX Option Pricing," Journal of Futures Market, Vol. 29, No. 6, 2009, pp. 523-543. doi:10.1002/fut.20387 


\section{Appendix A}

S\&P $500{ }^{\circledR}$ index options contract specifications.

\begin{tabular}{|c|c|}
\hline Symbol & SPX \\
\hline Underlying & The Standard \& Poor's 500 cash Index. \\
\hline Multiplier & $\$ 100$. \\
\hline Premium Quote & $\begin{array}{l}\text { Stated in decimals. One point equals } \$ 100 \text {. Minimum tick for options trading below } 3.00 \text { is } 0.05(\$ 5.00) \text { and for all } \\
\text { other series, } 0.10(\$ 10.00) \text {. }\end{array}$ \\
\hline Strike Prices & $\begin{array}{l}\text { In-, at- and out-of-the-money strike prices are initially listed. New series are generally added when the underlying } \\
\text { trades through the highest or lowest strike price available. }\end{array}$ \\
\hline Strike Price Intervals & Five points. 25-point intervals for far months. \\
\hline Expiration Date & Saturday following the third Friday of the expiration month. \\
\hline Exercise Style & European-SPX options generally may be exercised only on the last business day before expiration. \\
\hline Last Trading Day & $\begin{array}{l}\text { Trading in SPX options will ordinarily cease on the business day (usually a Thursday) preceding the day on which the } \\
\text { exercise-settlement value is calculated. }\end{array}$ \\
\hline Settlement Value & $\begin{array}{l}\text { Exercise will result in delivery of cash on the business day following expiration. The exercise-settlement value, SET, } \\
\text { is calculated using the opening sales price in the primary market of each component security on the last business day } \\
\text { (usually a Friday) before the expiration date. The exercise-settlement amount is equal to the difference between the } \\
\text { exercise-settlement value and the exercise price of the option, multiplied by } \$ 100 \text {. }\end{array}$ \\
\hline Margin & $\begin{array}{l}\text { Purchases of puts or calls with } 9 \text { months or less until expiration must be paid for in full. Writers of uncovered puts or } \\
\text { calls must deposit/maintain } 100 \% \text { of the option proceeds* plus } 15 \% \text { of the aggregate contract value (current index } \\
\text { level } \times \$ 100 \text { ) minus the amount by which the option is out-of-the-money, if any, subject to a minimum for calls of } \\
\text { option proceeds }{ }^{*} \text { plus } 10 \% \text { of the aggregate contract value and a minimum for puts of option proceeds }{ }^{*} \text { plus } 10 \% \text { of } \\
\text { the aggregate exercise price amount. (For calculating maintenance margin, use option current market value instead of } \\
\text { option proceeds.) Additional margin may be required pursuant to Exchange Rule } 12.10 \text {. }\end{array}$ \\
\hline
\end{tabular}

\section{Appendix B}

VIX futures contract specifications.

\begin{tabular}{|c|c|}
\hline Contract Name & CBOE Volatility Index (VIX) Futures \\
\hline Description & $\begin{array}{l}\text { The CBOE Volatility Index is based on real-time prices of options on the S\&P } 500 \text { Index, listed on the Chicago } \\
\text { Board Options Exchange (Symbol: SPX), and is designed to reflect investors' consensus view of future (30-day) } \\
\text { expected stock market volatility. }\end{array}$ \\
\hline Contract Size & $\$ 1000$ times the VIX \\
\hline No-Bust Range & $\begin{array}{l}\text { CFE Rule 1202(l). The CFE error trade policy may only be invoked for 1) for trades executed during extended } \\
\text { trading hours for the VIX futures contract, the Exchange error trade policy may only be invoked for a trade price } \\
\text { that is greater than } 20 \% \text { on either side of the market price of the applicable VIX futures contract, and } 2 \text { ) for trades } \\
\text { executed during regular trading hours for the VIX futures contract, the Exchange error trade policy may only be } \\
\text { invoked for a trade price that is greater than } 10 \% \text { on either side of the market price of the applicable VIX futures } \\
\text { contract. In accordance with Policy and Procedure III, the Help Desk will determine what the true market price for } \\
\text { the relevant Contract was immediately before the potential error trade occurred. In making that determination, the } \\
\text { Help Desk may consider all relevant factors, including the last trade price for such Contract, a better bid or offer } \\
\text { price, a more recent price in a different contract month and the prices of related contracts trading in other markets. }\end{array}$ \\
\hline Termination of Trading & $\begin{array}{l}\text { The close of trading on the day before the Final Settlement Date. When the last trading day is moved because of a } \\
\text { CFE holiday, the last trading day for expiring VIX futures contracts will be the day immediately preceding the last } \\
\text { regularly-scheduled trading day. }\end{array}$ \\
\hline Final Settlement Date & $\begin{array}{l}\text { The Wednesday that is thirty days prior to the third Friday of the calendar month immediately following the } \\
\text { month in which the contract expires ("Final Settlement Date"). If the third Friday of the month subsequent to } \\
\text { expiration of the applicable VIX futures contract is a CBOE holiday, the Final Settlement Date for the contract } \\
\text { shall be thirty days prior to the CBOE business day immediately proceeding that Friday. }\end{array}$ \\
\hline Final Settlement Value & $\begin{array}{l}\text { The final settlement value for VIX futures shall be a Special Opening Quotation (SOQ) of VIX calculated from the } \\
\text { sequence of opening prices of the options used to calculate the index on the settlement date. The opening price for } \\
\text { any series in which there is no trade shall be the average of that option's bid price and ask price as determined at } \\
\text { the opening of trading. The final settlement value will be rounded to the nearest } \$ 0.01 \text {. If the final settlement value } \\
\text { is not available or the normal settlement procedure cannot be utilized due to a trading disruption or other unusual } \\
\text { circumstance, the final settlement value will be determined in accordance with the rules and bylaws of The } \\
\text { Options Clearing Corporation. }\end{array}$ \\
\hline Delivery & $\begin{array}{l}\text { Settlement of VIX futures contracts will result in the delivery of a cash settlement amount on the business day } \\
\text { immediately following the Final Settlement Date. The cash settlement amount on the Final Settlement Date shall } \\
\text { be the final mark to market amount against the final settlement value of the VIX futures multiplied by } \$ 1000.00 \text {. }\end{array}$ \\
\hline
\end{tabular}

Source: CBOE Delayed Quotations. 